\title{
Natural rubber latex-clay nanocomposite: use of montmorillonite clay as an alternative for conventional $\mathrm{CaCO}_{3}$
}

\author{
A. Amarasiri ${ }^{1}$, U.N. Ratnayake ${ }^{2 *}$, U.K. De Silva ${ }^{1}$, S. Walpalage ${ }^{1}$ and S. Siriwardene ${ }^{2}$ \\ ${ }^{1}$ Department of Chemical and Process Engineering, Faculty of Engineering, University of Moratuwa, Katubedda, Moratuwa. \\ ${ }^{2}$ Rubber Research Institute, Telawala Road, Ratmalana.
}

\begin{abstract}
Natural rubber (NR) latex-clay nanocomposite (NRLCN) synthesized with montmorillonite (MMT) clay aqueous dispersion was evaluated for reinforcement and barrier properties. The physio-mechanical properties of the NRLCN were compared with the conventional NR latex composites containing $\mathrm{CaCO}_{3}$. The NRLCN structure was characterized with X-ray diffraction and scanning electron microscope techniques. The X-ray diffraction data showed that, with a lower concentration of clay, a highly exfoliated clay structure was achieved whilst the clay aggregation gradually resulted in a higher concentration of clay.
\end{abstract}

The crosslink density as computed based on the solvent absorption data of the latex nanocomposite films was increased with the increase of clay concentration. As a result of nanoscale dispersion of the montmorillonite clay and higher crosslink density of the latex nanocomposite films, the resistance to permeation of small molecules through the NRLCN was significantly enhanced in comparison to conventional NR latex- $\mathrm{CaCO}_{3}$ composites. Solid state mechanical properties of NRLCNs showed a significant reinforcement effect of dispersed clay platelets but without significantly reducing the elastic properties. The higher mechanical properties and improved barrier resistance indicated that NR latex nanocomposites containing montmorillonite clay is a potential replacement for conventional NR latex composites containing $\mathrm{CaCO}_{3}$.

Keywords: Barrier properties, clay, crosslink density, exfoliation, nanocomposites, natural rubber latex.

\section{INTRODUCTION}

Natural rubber (NR) latex is a stable colloidal suspension of negatively charged rubber particles and other non rubber substances in minor quantities and it is the main raw material for latex based products, especially for the manufacture of dipped products such as medical and industrial gloves. In general, conventional ground $\mathrm{CaCO}_{3}$ and China clay are used as non-reinforcing fillers in latex compounds to improve the cost-performance ratio of the dipped products. However, it is known that addition of these non-reinforcing fillers reduces the mechanical properties, especially the strength characteristics of latex films (Cai et al., 2003). In addition, higher loading levels of these inorganic particulate fillers impart stiffness to the latex films and as a result reduce the flexibility, one of the most important properties of latex gloves.

Polymer-clay nanocomposites have inspired the scientific and industrial community as an alternative for conventional polymeric composites since the Toyota Research Group for the first time, synthesized polyamide 6/clay nanocomposites with improvements in the mechanical and thermal properties in comparison to the pure polymer and conventional composites (Kojima et al., 1993). Montmorillonite (MMT) clay, which belongs to the family of $2: 1$ layered silicates, is the most researched clay mineral for preparing polymeric nanocomposites. MMT clay crystals are made of a large number of individual clay platelets/layers with a $1 \mathrm{~nm}$ thickness and a few microns in other dimensions (Brindley \& Brown, 1980; Ray \& Okamotoa, 2003). These clay platelets have a higher aspect ratio of 50 - 300 and a specific surface area of $750-800 \mathrm{~m}^{2} / \mathrm{g}$ (Utracki, 2004). The clay platelets are separated by a gallery space, which consists of hydrated cations such as $\mathrm{Na}^{+}, \mathrm{K}^{+}$and water molecules. It has been identified that several active sites such as a few positive charges, - $\mathrm{OH}$ groups and negative charges are present on the surface of MMT clay crystals (Utracki, 2004). 
In recent years, natural rubber (NR)/ clay nanocomposites have also drawn attention among other polymeric nanocomposites because of the higher reinforcement and other functional properties such as barrier resistance and flame retardancy, which were achieved with a lower clay loading (Varghese \& Karager - Kocsis, 2003). There are a few types of processing methods that have been developed for preparing NR/clay nanocomposites (Galimberrti, 2011) out of which melt intercalation and latex compounding are the most industrially applicable methods. However, NR latex/clay nanocomposite (NRLCN) films were prepared with the conventional compounding technique, provided that nanoscale aqueous dispersion of clay is formed in situ (Wu et al., 2005). Montmorillonite clay has an inherent hydrophilic nature, and as a result it is readily dispersed in water, which acts as a swelling agent. Dispersed clay particles in water have a higher gallery space and finally the exfoliation/delaminating of clay into individual platelets occurs with increasing water content in the dispersion, resulting in nanoscale dispersion (Varghese \& Karager - Kocsis, 2003). There is a bound hydrated layer around the NR latex particles (Blackley, 1997). Hence, the hydrated layer of these latex particles may attract the clay platelets and is likely to interact with latex particles. Valadares et al. (2006) has also reported the synthesis of un-vulcanized natural rubber latex/clay nanocomposites using aqueous dispersion of montmorillonite clay. It was also shown that there is a strong adhesion at the rubberclay interface and as a result the mechanical properties of the nanocomposites is enhanced (Valadares et al., 2006). Clay dispersion at nanoscale in the NR latex and strong interaction between rubber and clay are the main factors for enhanced physical properties of NR latex/clay nanocomposites.

According to the free volume concept, the chain mobility provides a driving force for the diffusion of small molecules. In a nanocomposite, the molecular mobility is severely reduced in the close vicinity of the clay platelets because of the stronger interface formed between the clay and polymer matrix, and thus provides a torturous pathway for the permeating molecules, which increase the barrier resistance (Jacob et al., 2008). Although the the addition of MMT clay enhances the physical properties of NR latex films, the maximum potential of MMT clay is yet to be achieved because of the limited degree of exfoliation of clay within the NR latex films. In addition, a majority of the work reported in literature has suggested that the reinforcement of rubber/ clay nanocomposites occurred due to the microstructure of clay in rubber and the strong adhesion between clay and rubber (Hwang et al., 2004; Valadares et al., 2006). The objectives of the study reported here were to prepare NR latex/clay nanocomposites using aqueous dispersion of MMT clay nanocomposites, and to determine the effect of MMT clay structure and concentration on reinforcement and barrier properties of the nanocomposites. The reinforcement behaviour was examined with respect to clay dispersion, crosslink density and strain induced crystallization. The physical properties of NRLCN prepared using MMT clay were compared with conventional $\mathrm{NR}$ latex $/ \mathrm{CaCO}_{3}$ composites as a potential alternative in making latex dipped products.

\section{METHODS AND MATERIALS}

\section{Materials}

Sodium montmorillonite ( $\mathrm{Na}$ Cloisite) clay supplied by Southern Clay Products, USA, with a cation exchange capacity of $80 \mathrm{meq} / 100 \mathrm{~g}$ and an interlayer distance of $1.24 \mathrm{~nm}$ was used as the clay mineral. Ground $\mathrm{CaCO}_{3}$ of commercial grade with a density of $2.7 \mathrm{~g} / \mathrm{cm}^{3}$ was used to prepare conventional NR latex composites. Centrifuged NR latex with a total solid content (TSC) of $62 \%$ was supplied by Lalan Rubbers (Pvt) Ltd., Sri Lanka. The compounding chemicals were of commercial grade and supplied by Glorchem Chemicals, Sri Lanka.

\section{Preparation of NR latex/clay nanocomposite (NRLCN)}

The aqueous dispersion of 2.5 wt \% montmorillonite (MMT) clay was prepared by adding $0.5 \mathrm{wt} . \%$ sulphonate as dispersing additive and mixing with a magnetic stirrer at $50^{\circ} \mathrm{C}$ for $2 \mathrm{~h}$. Other dispersions of compounding ingredients were prepared by conventional ball milling technique.

The compounded latex was prepared according to the formulation given in Table 1 (Pendle \& Gorton,1980) and it was left for maturation for $16 \mathrm{hrs}$. The total solid content of the compounded latex was reduced to $30 \%$ before the addition of either MMT clay or $\mathrm{CaCO}_{3}$ dispersions. NR latex/MMT clay and NR latex $/ \mathrm{CaCO}_{3}$ films with a uniform thickness were casted on glass plates and air dried until it became transparent. These films were subsequently vulcanized at $120^{\circ} \mathrm{C}$ for $20 \mathrm{~min}$ in an air circulated oven. As shown in Table 1, NR latex/ clay nanocomposites (NRLCN) were prepared with varying concentrations of MMT clay from $1-6 \mathrm{phr}$ 
while $\mathrm{NR}$ latex $/ \mathrm{CaCO}_{3}$ mix 1 composites were prepared with varying concentrations of $\mathrm{CaCO}_{3}$ from $1-6$ phr. In addition, $\mathrm{NR}$ latex $/ \mathrm{CaCO}_{3}$ mix 2 composites were also prepared with a higher concentration of $\mathrm{CaCO}_{3}$ ranging from 10 - 60 phr in order to make conventional NR latex/ $\mathrm{CaCO}_{3}$ composites similar to that used in industrial applications.

\section{Characterization of NR latex/clay nanocomposite (NRLCN)}

X-ray diffraction (XRD) technique was used to evaluate the intercalation/exfoliation behaviour of MMT clay in the NR matrix. XRD analysis of the NRLCN films was performed with a Bruker D8 diffractometer at a wave length of $1.54 \AA$ of $\mathrm{Cu} \mathrm{K} \alpha$ radiation, scanning over a Bragg angle $(2 \theta)$ ranging from $1-10^{\circ}$ at a rate of $0.01 \%$ s. The conventional Bragg equation $(\mathrm{n} \lambda=2 \mathrm{~d} \sin \theta)$ was used to calculate the interlayer spacing of the MMT clay in the nanocomposite materials where, $\lambda$ is the wave length of $\mathrm{X}$-rays, $\mathrm{d}$ is the crystal lattice spacing, $\theta$ is the angle between incident radiation and the scattering plane, and $n$ is the order of diffraction.

The morphology of clay and its dispersion within the NR latex nanocomposite vulcanisate materials was observed under a scanning electron microscope (SEM), (Hitachi SU 6600), at an acceleration voltage of $25 \mathrm{kV}$. Cross section of the nanocomposite films was gold plated before observing under SEM.

\section{Solvent transportation properties}

The solvent transportation properties were studied by analyzing the solvent absorption behaviour of the NRLCN using toluene at room temperature $\left(30{ }^{\circ} \mathrm{C}\right)$.
Circular specimens of the nanocomposite films with a diameter of $2 \mathrm{~cm}$ were weighed using an analytical balance with an accuracy of $\pm 0.1 \mathrm{mg}$. The samples were immersed in $25 \mathrm{~mL}$ of toluene under air tight conditions for $48 \mathrm{~h}$ and the surface adhered solvent was wiped off using a filter paper. The samples were kept in an air tight weighing bottle without allowing the solvent to evaporate and the weight was taken as the equilibrium weight. The sample was dried at $100{ }^{\circ} \mathrm{C}$ for more than $24 \mathrm{hrs}$ till it attained a constant weight, which was taken as the deswollen weight.

The permeability of a solvent into the NR matrix depends upon the absorptivity and crosslink density of the latex films. The absorption coefficient $(S)$ was calculated using the following equation (Aprem et al., 2000).

$$
S=\frac{W_{S}}{W}
$$

where $W_{S}$ is the weight of the solvent at equilibrium swelling and $W$ is the initial weight of the sample.

The crosslink density $(\gamma)$ of the NR latex-clay nanocomposite was calculated using the following equation.

$$
\gamma=\frac{1}{2 M_{C}}
$$

$M$ is the molar mass between the crosslinks of the rubber nanocomposites and it was calculated using the Flory Rehner equation. (Flory \& Rehner, 1943; Khinnavar \& Aminabhavi, 1991).

Table 1: Compound formulation for NR latex/ montmorillonite clay and NR latex $/ \mathrm{CaCO}_{3}$ composites

\begin{tabular}{lccc}
\hline $\begin{array}{c}\text { Compounding } \\
\text { ingredients }\end{array}$ & $\begin{array}{c}\text { NR latex/clay } \\
\text { Dry, phr }\end{array}$ & $\begin{array}{c}\mathrm{NR} / \mathrm{CaCO}_{3} \text {-mix } 1 \\
\text { Dry, phr }\end{array}$ & $\begin{array}{c}\mathrm{NR} / \mathrm{CaCO}_{3} \text {-mix } 2 \\
\text { Dry, phr }\end{array}$ \\
\hline Centrifuged latex & 100 & 100 & 100 \\
$10 \% \mathrm{KOH}$ & 0.3 & 0.3 & 0.3 \\
$20 \%$ potassium laureate & 0.2 & 0.2 & 0.2 \\
$50 \%$ sulphur & 0.5 & 0.5 & 0.5 \\
$50 \%$ ZDEC a & 0.75 & 0.75 & 0.75 \\
$50 \%$ ZnO & 0.25 & 0.25 & 0.25 \\
$50 \%$ Nonoxwsp & 0.5 & 0.5 & 0.5 \\
$2.5 \% \mathrm{MMT}_{\text {clay }}$ & $1-6$ & - & - \\
$50 \% \mathrm{CaCO}_{3}$ & - & $(1,2,3,4,5,6)$ & $(10,20,30,40,50,60)$ \\
\hline
\end{tabular}

a Zinc diethyldithio carbomate 


$$
M_{c}=\frac{-\rho_{p} V_{s}\left(V_{r}\right)^{1 / 3} x}{\ln \left(1-V_{r}\right)+V_{r}+x\left(V_{r}\right)^{2}}
$$

where $\rho_{p}$ is the density of the rubber $\left(0.92 \mathrm{~g} / \mathrm{cm}^{3}\right), V_{s}$ is the molar volume of toluene $\left(106 \mathrm{~cm}^{3}\right), V_{r}$ is the volume fraction of rubber in the swollen rubber and $x$ is the rubber toluene interaction parameter (0.42). The volume fraction of rubber $\left(V_{r}\right)$ in the swollen gel was calculated using the Ellis and Welding equation. (Ellis \& Welding, 1964; Cassidy et al., 1983).

$$
V_{r}=\frac{(D-F T) / \rho_{r}}{(D-F T) / \rho_{r}+A_{o} / \rho_{s}}
$$

where $D$ is the de-swollen weight, $F$ is the weight fraction of the filler (clay), $A_{o}$ (in this experiment $W_{s}$ ) is the solvent absorbed, $T$ is the initial sample weight $(W)$, $\rho_{r}$ is the specific gravity of rubber $(0.92)$ and $\rho_{s}$ is the specific gravity of the solvent $(0.87)$.

\section{Vulcanizate properties of NRLCN and conventional $\mathrm{NR}$ latex $/ \mathrm{CaCO}_{3}$ composites}

The mechanical properties of the NRLCN vulcanizates were determined to evaluate the reinforcing effect of MMT clay on NR latex compounds with respect to the conventional NR latex composites $\left(\mathrm{NR} / \mathrm{CaCO}_{3}\right.$-mix 2) containing higher loading of $\mathrm{CaCO}_{3}$. Tensile property measurements were performed with dumbbell shaped specimens according to the ASTM D-412 with Hounsfield universal tensometer. Tensile measurements were carried out at a crosshead speed of $500 \mathrm{~mm} / \mathrm{min}$.
The tear strength was determined using crescent shaped samples according to ASTM D-624-00 using the same universal tensometer.

\section{RESULTS AND DISCUSSION}

NRLCN films were characterized with X-ray diffractometry to examine the clay morphology within the latex films. Figure 1-a illustrates the X-ray diffraction patterns of the NR latex films prepared with different loadings of clay, whilst Table 2 presents the diffraction peak positions and corresponding interlayer spacing of the MMT clay in each nanocomposite film. The characteristic diffraction peak $\left(\mathrm{d}_{001}\right)$ of Na-MMT clay is at $7.04^{\circ}$ (Figure 1-b) and the corresponding interlayer spacing is $12.6 \AA$ (Table 2). As shown in Figure 1-a, no prominent diffraction peak was observed when NRLCN was synthesized with lower MMT clay loadings below $3 \mathrm{phr}$, demonstrating mainly the exfoliated clay structure within the rubber matrix with these loading levels. Previous studies (Norrish, 1972; Wu et al., 2005) on $\mathrm{X}$-ray diffraction patterns of clay aqueous dispersions have shown a complete exfoliation of the clay particles with less than $10 \%$ concentration due to the swelling of the clay and subsequent delaminating of the clay particles into individual layers within the aqueous medium. Stephen et al. (2006) have also reported that the exfoliated clay platelets in the aqueous medium are either able to retain their exfoliated state when they are mixed with NR latex, or form extremely large regular ordered spacing between the clay platelets at less than $10 \mathrm{wt} \%$ clay concentrations. Based on above, it can be concluded that $2.5 \mathrm{wt}$. \% of clay dispersion prepared in the present study should have exfoliated clay platelets.

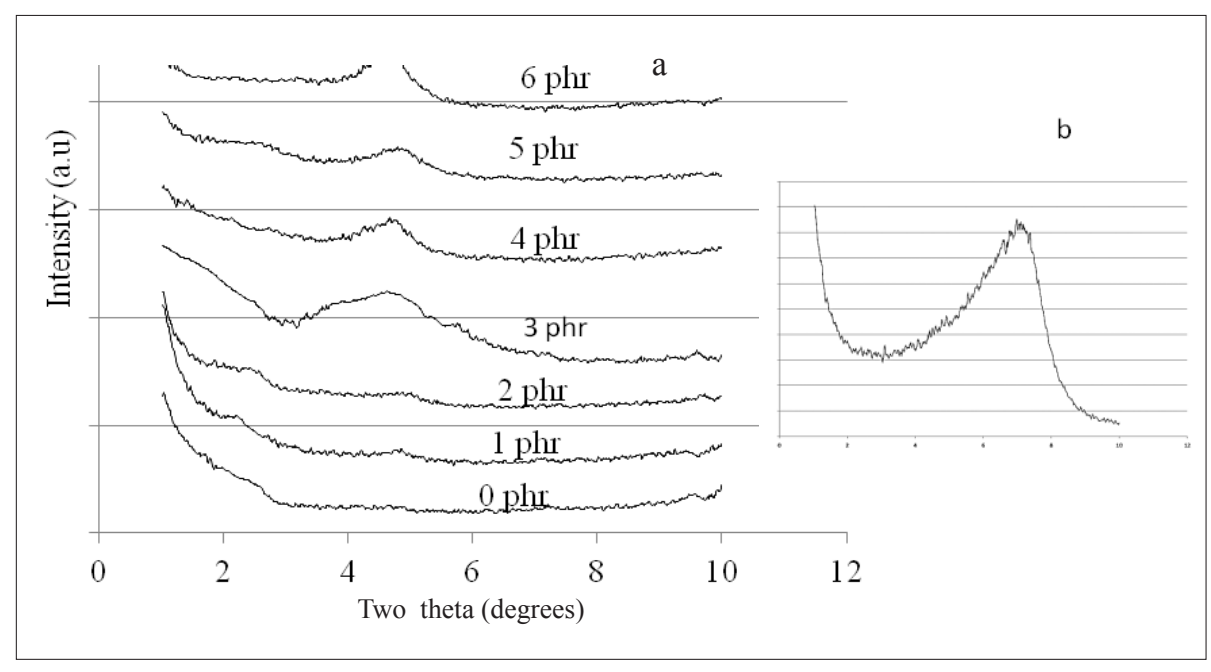

Figure 1: X-ray diffractograms of (a) NR latex/clay nanocomposites and (b) montmorillonite clay 
Table 2: Diffraction peak positions and interlayer distance of NR latex/montmorillonite clay nanocomposites

\begin{tabular}{ccc}
\hline $\begin{array}{c}\text { Montmorillonite clay } \\
\text { loading (phr) }\end{array}$ & $\begin{array}{c}\text { Peak position, } \\
2 \theta \text { (Degrees) }\end{array}$ & $\begin{array}{c}\text { Interlayer } \\
\text { distance }(\AA)\end{array}$ \\
\hline MMT clay & 7.04 & 12.6 \\
0 & - & - \\
1 & - & - \\
2 & - & - \\
3 & 4.61 & 19.2 \\
4 & 4.62 & 19.1 \\
5 & 4.67 & 18.9 \\
6 & 4.68 & 18.8 \\
\hline
\end{tabular}

As a result, the mostly exfoliated clay structure remained without reaggregating in the NR latex nanocomposite films when the clay concentration was below 3 phr. On the other hand, a broad diffraction peak appeared at $2 \theta$ of $4.61^{\circ}$ with a gallery spacing of $19.2 \AA$ when the NR nanocomposite film contained $3 \mathrm{phr}$ of clay (Figure 1-a). The diffraction peak has become narrower with the increase of clay concentration from 3 to $6 \mathrm{phr}$ in the nanocomposite structure. This indicates that, with the increase of clay loading above $3 \mathrm{phr}$, the aggregated clay structures within the nanocomposites films become dominant as the clay platelets begin to reorganize into stacks with a slight increase in inter-gallery spacing than the pure MMT clay. This clearly shows that during the drying process, as the clay loading increases, the clay platelets begin to form aggregated structures from the exfoliated state.
Figure 2 shows a SEM image of NRLCN film containing $2 \mathrm{phr}$ of montmorillonite clay. As shown in the Figure, the clay platelets are dispersed uniformly throughout the latex film. This would suggest that when the clay aqueous dispersion is added into the NR latex, the clay platelets remained dispersed without aggregating during the formation of latex nanocomposite films.

As shown in Table 3, there is a $28 \%$ increase in the crosslink density of the NRLCN nanocomposite containing $1 \mathrm{phr}$ of MMT clay, compared to the NR latex film without clay. Jacob et al. (2008) also reported a similar effect of clay on crosslink density as the compatibility between the exfoliated clay platelets and the rubber matrix was improved. These hydrophilic clay platelets with a higher surface area could attract hydrated latex particles, which were negatively charged and interact with exfoliated clay platelets through positive charges at the edges of clay platelets, resulting in a higher crosslink density. However, beyond $1 \mathrm{phr}$ of MMT clay, the crosslink density of the nanocomposite film vulcanizates increased gradually but at a lower rate. This is attributed to the fact that, with the increase of clay loading, the aggregated clay structures become dominant resulting in reduced surface area of the clay. Hence once the clay platelets start to re-aggregate with the increase of clay loading, the amount of available clay platelets (active sites) in the latex medium begins to decrease. In contrast to $\mathrm{NRLCN}, \mathrm{NR}$ latex $/ \mathrm{CaCO}_{3}$ composites consisting of similar loading levels as the MMT clay did not show a significant variation in crosslink density with the increase of $\mathrm{CaCO}_{3}$ loading, demonstrating that there

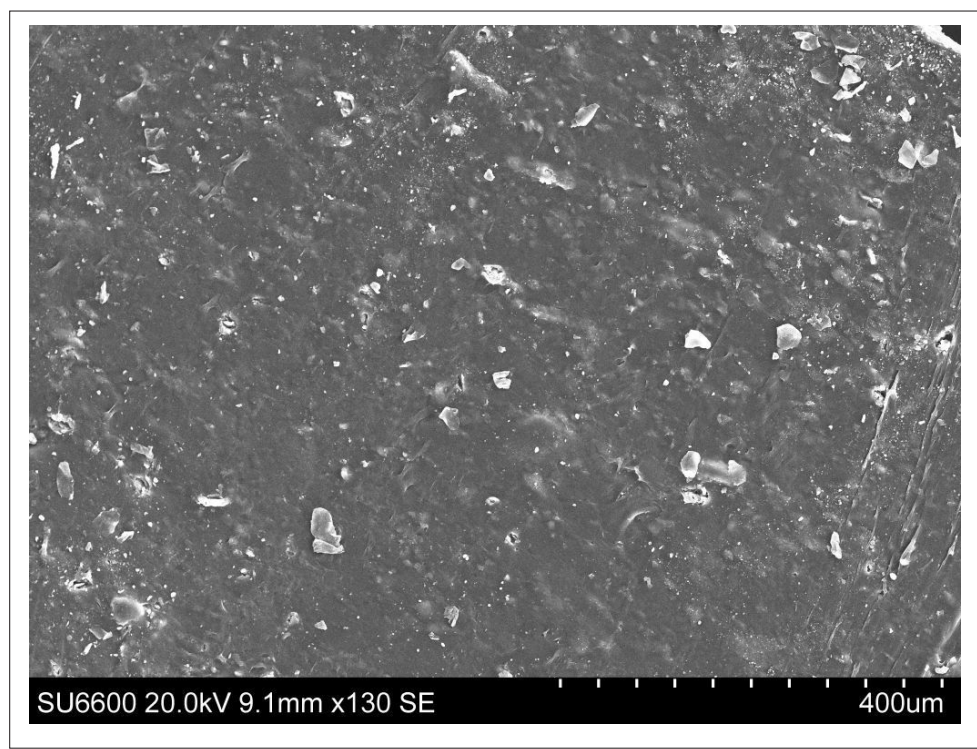

Figure 2: SEM image of NR latex/clay nanocomposite with 2 phr loading 
is no interaction between $\mathrm{CaCO}_{3}$ and rubber. Therefore crosslink density is only dependent on the vulcanization system, as expected, since conventional $\mathrm{CaCO}_{3}$ filler acts as a diluent filler in the latex formulation.

Table 3 also illustrates the solvent absorption behaviour of both NR latex nanocomposites containing clay and the conventional composites containing $\mathrm{CaCO}_{3}$. The solvent absorption co-efficient of the NRLCN has gradually reduced with the increase of clay loading whereas no significant difference was observed in NR latex $/ \mathrm{CaCO}_{3}$ composite samples. These solvent absorption data are clear evidence of the enhanced barrier for solvent transportation through the nanocomposite films when MMT clay loading was increased. Aprem et al. (2006) has also showed a decrease in the solvent absorption coefficient of NR latex/clay nanocomposites due to the exfoliated clay platelets acting as a plate-like structure and forming crosslinks, which prevents solvent transportation through the rubber matrix. Valdares et al. (2006) further explained that a blend of exfoliated and intercalated clay structures within the rubber matrix impart synergistic contribution to the barrier resistance. Hence it is possible to offer more barrier resistance of the rubber matrix by blending exfoliated and aggregated clay platelets at higher clay loadings. The NR latex/ $\mathrm{CaCO}_{3}$ micro composites did not show any significant resistance to the solvent absorption since there were no improvements in the crosslink densities. Also there was no significant physical hindrance by the $\mathrm{CaCO}_{3}$ at these loadings, which did not have card-like structures as the clay platelets in the rubber matrix.

The tensile properties of the NRLCN vulcanizates containing different loadings of MMT clay (i.e. $1-6 \mathrm{phr}$ ) were examined to evaluate the reinforcing effect of the dispersed clay minerals, and to compare with the tensile properties of the conventional NR latex composites

Table 3: Solvent absorption coefficient and crosslink density of the NR latex composites

\begin{tabular}{|c|c|c|c|c|}
\hline \multirow{2}{*}{$\begin{array}{l}\mathrm{MMT} / \\
\mathrm{CaCO}_{3} \\
\text { Loading }\end{array}$} & \multicolumn{2}{|c|}{ NR latex-clay nanocomposite } & \multicolumn{2}{|c|}{ NR latex- $\mathrm{CaCO}_{3}-$ mix 1} \\
\hline & $\begin{array}{c}\text { Solvent } \\
\text { absorption } \\
\text { coefficient (S) }\end{array}$ & $\begin{array}{c}\text { Crosslink } \\
\text { density (v) } \\
\mathrm{mol} / \mathrm{g} \times 10^{-5}\end{array}$ & $\begin{array}{c}\text { Solvent } \\
\text { absorption } \\
\text { coefficient (S) }\end{array}$ & $\begin{array}{r}\text { Crosslink } \\
\text { density (v) } \\
\mathrm{mol} / \mathrm{g} \times 10^{-5}\end{array}$ \\
\hline 0 & 4.53 & 4.83 & 4.53 & 4.83 \\
\hline 1 & 4.45 & 6.17 & 4.53 & 5.84 \\
\hline 2 & 4.35 & 6.30 & 4.52 & 5.74 \\
\hline 3 & 4.25 & 6.43 & 4.51 & 5.63 \\
\hline 4 & 4.09 & 6.75 & 4.50 & 5.54 \\
\hline 5 & 3.96 & 7.00 & 4.49 & 5.44 \\
\hline 6 & 3.84 & 7.27 & 4.48 & 5.23 \\
\hline
\end{tabular}

containing $\mathrm{CaCO}_{3}$. Figures $3-6$ illustrate the tensile properties and tear strength of the NRLCN and NR latex $/ \mathrm{CaCO}_{3}$ composites. The tensile strength (Figure 3 -a) of the NRLCN vulcanizates nanocomposites was increased with the increase in MMT clay concentration, demonstrating the significant reinforcing effect of clay platelets in the nanocomposite material. For example, the tensile strengths of NRLCNs containing $3 \mathrm{phr}$ and $6 \mathrm{phr}$ were increased by about $40 \%$ and $60 \%$, respectively in comparison to the NR latex gum compound containing no clay. However, as shown in Figure 3-a, the rate of increase was comparatively higher up to $3 \mathrm{phr}$, and beyond that the rate of increase in tensile strength was reduced. At lower clay loadings below $3 \mathrm{phr}$, the clay morphology within the nanocomposite material is mostly in exfoliated state $(1 \mathrm{~nm})$ and smaller stacks with a few clay platelets as confirmed by XRD. As a result, the aspect ratio as the well as the specific surface area of the clay platelets is higher in the NRLCN containing lower clay loading levels and hence a higher resistance to rupture upon stretching was observed. However, with the gradual increase of clay loading above $3 \mathrm{phr}$, the clay morphology in the nanocomposite material is changed from a mainly exfoliated structure to an aggregated clay structure as explained by XRD data (Figure 1). The aggregated clay structures tend to reduce the tensile strength compared to exfoliated clay platelets because of the reduced aspect ratio and the specific surface area of clay aggregates. Nevertheless, the crosslink density gradually increases as clay loading increases (Table 3 ) in the latex films. As a result of both these effects, beyond $3 \mathrm{phr}$ of clay, the tensile strength of NRLCN vulcanizates was increased at a lower rate compared to that of the NRLCN containing lower clay loadings. On the other hand, the NR latex $/ \mathrm{CaCO}_{3}$ composites showed (Figure 3-b) a gradual reduction of tensile strength with increasing $\mathrm{CaCO}_{3}$ loading as expected. In general, sub-micron scale $\mathrm{CaCO}_{3}$ acts as a non-reinforcing particulate filler. Hence, the addition of $\mathrm{CaCO}_{3}$ would reduce the strength characteristics of the latex composite because of the limited interaction between the particulate filler and the rubber molecules.

Figure $4-\mathrm{a}$ and $4-\mathrm{b}$ show the tensile modulus of NRLCN vulcanizates and conventional NR latex/ $\mathrm{CaCO}_{3}$ composite vulcanizates, respectively. In comparing these two vulcanizates, it clearly shows that NRLCNs have a significantly higher modulus with a lower clay loading (i.e. $1-6 \mathrm{phr}$ ) than the conventional composites containing even a higher loading of $\mathrm{CaCO}_{3}$ $(10-60 \mathrm{phr})$, indicating a higher reinforcement imparted by MMT clay. Importantly, although the modulus at $500 \%$ elongation (M500) of the NR latex gum vulcanizates is $0.9 \mathrm{MPa}$ (Figure 4-a), there is a remarkable increase in 


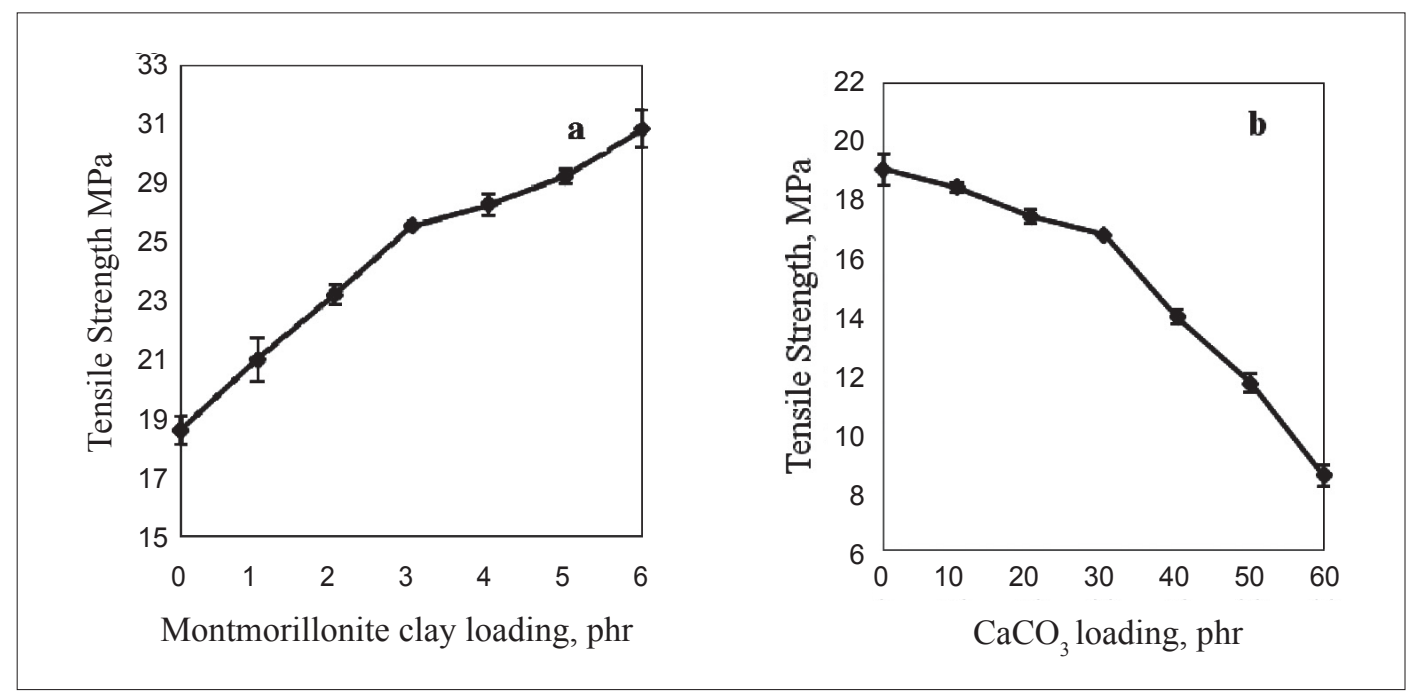

Figure 3: Tensile strength of (a) NR latex/clay nanocomposites and (b) $\mathrm{NR}$ latex $/ \mathrm{CaCO}_{3}$ composites

M500 with increasing the clay content. The modulus of M500 of NRLCN containing $2 \mathrm{phr}$ and $6 \mathrm{phr}$ of clay were 3.2 MPa and 5.5 MP, an increase of $256 \%$ and $511 \%$, respectivly, with respect to the gum compound. Similar reinforcing effects of the clay on NR latex films have been explained as due to the formation of immobilized rubber molecules close to the clay platelets dispersed within the rubber matrix (Mathew \& Varghese, 2005). Mathew \& Varghese (2005) further showed that the exfoliated clay sheets/platelets oriented towards the strain direction. It is well known that natural rubber has a characteristic feature of strain induced crystallization. The NR molecules start to align towards the direction of stress when it is stretched to about $300 \%$ or above , and as a result show a comparatively higher modulus and strength upon stretching. Uniform dispersion of clay at nanoscale within the NRLCN films would further promote the strain induced crystallization, resulting in a higher modulus at $500 \%$ elongation. These results further confirm the presence of exfoliated clay platelets and clay stacks with a few platelets, which are of nanoscale thickness in the NRLCN materials. The increased crosslink density, as shown in Table 3, has also contributed to the higher modulus achieved in the nanocomposite films containing MMT clay. On the other hand, it is evident from Figure 4-b that conventional $\mathrm{CaCO}_{3}$ does not reinforce the latex films, but a slight increase of modulus was resulted due to the presence of higher loading of inorganic minerals in the latex films.

As shown in Figure 5-a, despite the significant increase in modulus values of the NRLCN vulcanizates, the

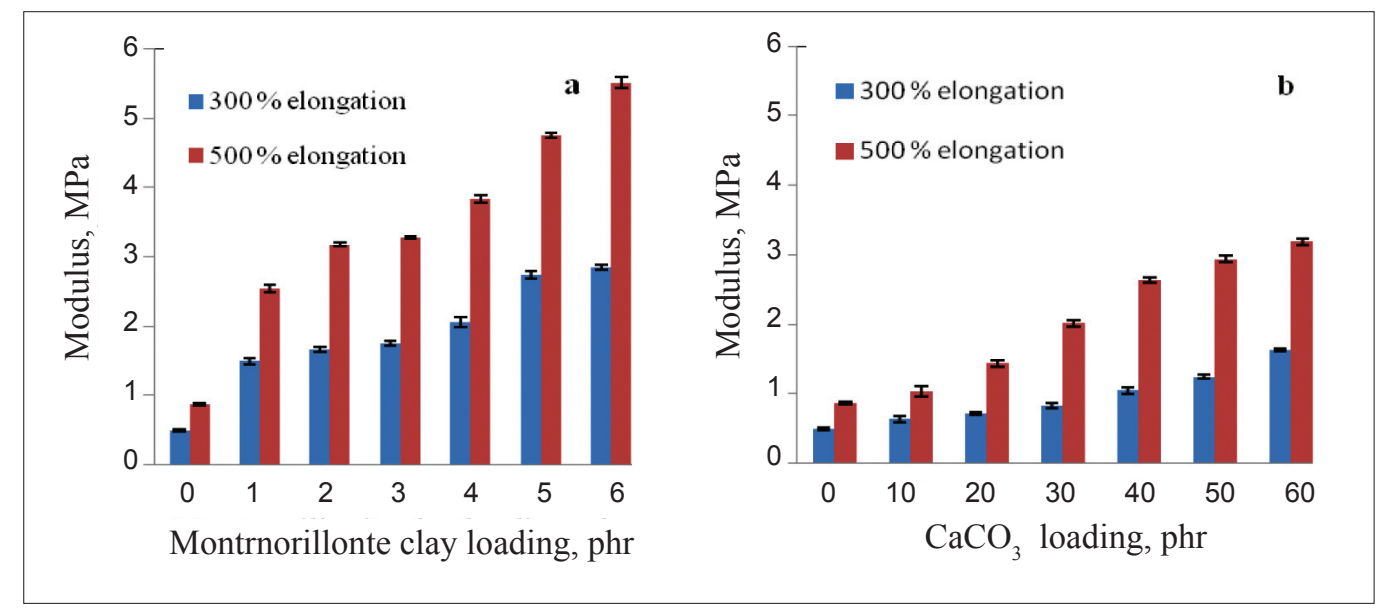

Figure 4: Tensile modulus of (a) NR latex/clay nanocomposites and (b) $\mathrm{NR}$ latex $/ \mathrm{CaCO}_{3}$ composite 


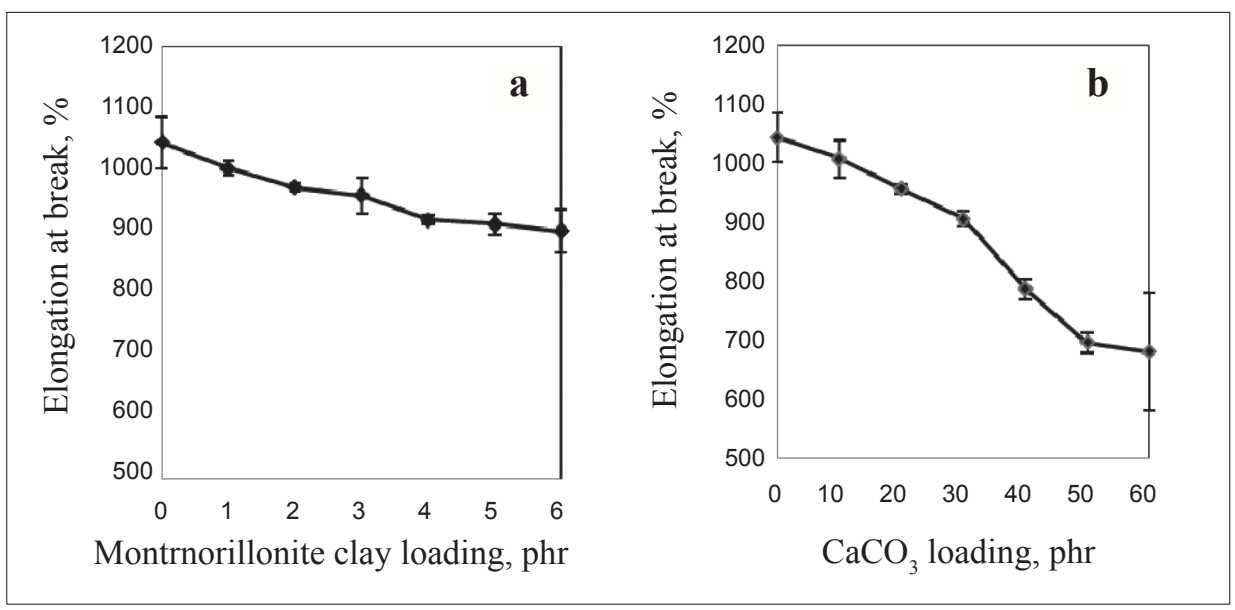

Figure 5: Elongation at break of (a) NR latex/clay nanocomposite and (b) NR latex/CaCO3 composite

elongation at break reduced marginally with increasing clay loading. However, the elongation at break of the NR latex $/ \mathrm{CaCO}_{3}$ composites were reduced significantly when the $\mathrm{CaCO}_{3}$ loading was increased from $0-60 \mathrm{phr}$ (Figure 5-b) as a higher $\mathrm{CaCO}_{3}$ level reduces the rubber content, and also $\mathrm{CaCO}_{3}$ aggregates interfere with the chain mobility. This would be one of the major drawbacks in making latex dipped articles, especially latex gloves, with a higher loading of $\mathrm{CaCO}_{3}$. This would suggest that the NRLCN retains its elastic behaviour and as a result it may have a better flexibility than the conventional NR latex $/ \mathrm{CaCO}_{3}$ composite. This is a proof that the clay reinforces the NR latex nanocomposite vulcanizates whilst maintaining a good elasticity.

Figure 6 shows the tear strength of the NRLCN and the NR latex $/ \mathrm{CaCO}_{3}$ conventional composites. Good tear strength is one of the major requirements for dipped products, especially for latex gloves. Similar to the tensile properties, the tear strength of the nanocomposite vulcanizates was enhanced with increased nanoclay concentrations (Figure 6-a) whereas the conventional composites showed a gradual decrease (Figure 6-b). This occurs when the layered clay platelets/smaller stacks with a few clay platelets, which are at nanoscale obstruct the tearing path of micro-cracks of the nanocomposite films. As a consequence, the resistance to tearing the nanocomposite vulcanizate films increase whereas sub micron scale $\mathrm{CaCO}_{3}$ acts as a stress concentrator and therefore would promote the tearing of latex films. Increased crosslink density of the NRLCN also has a positive effect on the tear strength of the nanocomposite materials (Mathew et al., 2005 ; Awang et al., 2006). Cai et al. (2003) also reported a similar reduction of the tear strength with the conventional filler filled NR latex vulcanizate films.

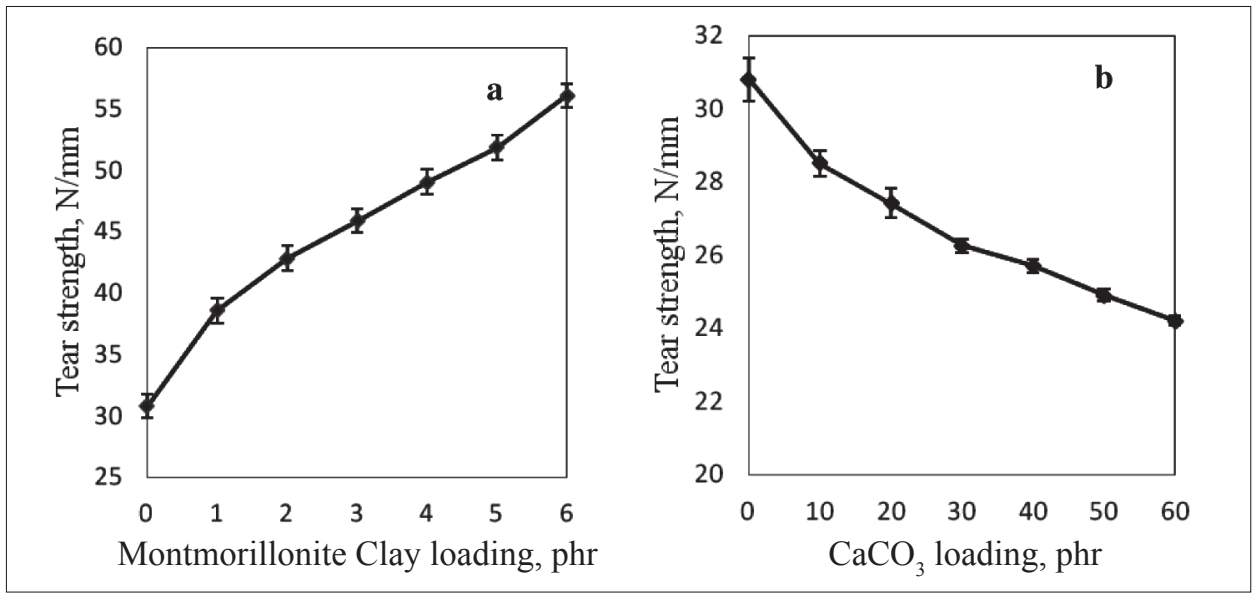

Figure 6: Tear strength of (a) NR latex/clay nanocomposite and (b) $\mathrm{NR}$ latex $/ \mathrm{CaCO}_{3}$ composite 


\section{CONCLUSION}

The NRLCN was successfully prepared with a higher degree of exfoliation using an aqueous dispersion of MMT clay. A clay loading of $2-3 \mathrm{phr}$ was found to be the optimum MMT level to achieve the highest degree of exfoliation within the nanocomposite. Increase in the crosslink density and the physical hindrance provided by the clay platelets network as a result of exfoliation of the clay particles are the major contributing factors for the enhancement of the barrier properties. The blend of exfoliated clay platelets and the favourable interactions between the clay platelets and the hydrated NR latex particles have offered a significant improvement in the physical properties such as the tensile properties and the tear strength characteristics. Addition of conventional $\mathrm{CaCO}_{3}$, a common filler in the latex dipping industry has shown inferior physical properties, especially at higher loading levels.

This research has shown that low loadings of MMT clay are able to significantly improve the reinforcement, whilst maintaining good elastic properties and barrier properties of the nanocomposite vulcanizates. As a result, the NRLCN is a potential replacement for the conventional NR latex microcomposites containing $\mathrm{CaCO}_{3}$ to manufacture of dipped products, particularly NR latex gloves.

\section{Acknowledgement}

This research project was supported by the University of Moratuwa Senate Research Grant Number 292. Authors also wish to acknowledge Lalan Rubbers (Pvt) Ltd. for providing materials and technical facilities.

\section{REFERENCES}

1. Aprem A.S., Joseph K., Mathew A.P. \& Thomas S. (2000). Sorption and diffusion of acrylonitrile monomer through crosslinked nitrile rubber. Journal of Applied Polymer Science 78(5): 941 - 952.

2. Aprem A.S., Jacob A. \& Pal S.N. (2006). Natural rubber latex-layered silicate nanocomposites with excellent permeation resistance and mechanical properties. In: Latex 2006. Proceedings of the $4^{\text {th }}$ Conference on Latex and Latex Based Products, 24 - 25 January, Rapra Technology, Frankfurt, Germany, pp. 25 - 30.

3. Awang S., Vivaygananathan K., Shamsul Bhari A.R. \& Amir Hashim M.Y. (2006). Effect of nano-sized fillers on prevulcanized natural rubber latex film properties,
In: Latex 2006. Proceedings of the $4^{\text {th }}$ Conference on Latex and Latex Based Products, 24 - 25 January. Rapra Technology, Frankfurt, Germany, pp. 149 - 161.

4. Blackley D.C. (1997). Polymer Lattices Science and Technology, $2^{\text {nd }}$ edition, volume 2, pp. 26. Chapman \& Hall, London, UK.

5. Brindley G.W. \& Brown G.(1980). Crystal Structure of Clay Minerals and their X-ray Identification, $3^{\text {rd }}$ edition, pp. 495. Mineralogical Society, London, UK.

6. Cai H.H., Li S.D., Rian T.G., Wang H.B. \& Wang J.H. (2003). Reinforcement of natural rubber latex film by ultrafine calcium carbonate. Journal of Applied Polymer Science 87(6): 982 - 985.

DOI: http://dx.doi.org/10.1002/app.11410

7. Cassidy P.E., Aminabhavi T.M. \& Thompson C.M. (1983). Water permeation through elastomers \& plastics. Rubber Chemistry and Technology 56(3): $594-618$.

DOI: http://dx.doi.org/10.5254/1.3538143

8. Ellis B. \& Welding G.N. (1964). Estimation from swelling of the structural contribution of chemical reactions to the vulcanization of natural rubber. II. Estimation of equilibrium degree of swelling. Rubber Chemistry and Technology 37(2): $571-575$.

DOI: http://dx.doi.org/10.5254/1.3540349

9. Flory P.J. \& Rehner J.R. (1943). Statistical mechanics of cross-linked polymer networks. II. swelling. Journal of Chemical Physics 11(11): 521 - 526.

DOI: http://dx.doi.org/10.1063/1.1723792

10. Galimberrti M. (2011). Rubber-clay Nanocomposites; Science, Technology and Applications. John Wiley and Sons Inc., Hoboken, New Jersey, USA. DOI: http://dx.doi.org/10.1002/9781118092866

11. Hwang W.G., Wei K.H. \& Wu C.M. (2004). Preparation and mechanical properties of nitrile butadiene rubber/ silicate nanocomposites. Polymer 45(16): 5729 - 5734. DOI: http://dx.doi.org/10.1016/j.polymer.2004.05.040

12. Jacob A., Kurian P. \& Aprem A.S. (2008). Transport properties of natural rubber latex layered clay nanocomposites. Journal of Applied Polymer Science 108(4): 2623 - 2629.

DOI: http://dx.doi.org/10.1002/app.26615

13. Khinnavar R.S. \& Aminabhavi T.M. (1991). Diffusion \& sorption of organic liquids through polymer membranes.I. Polyurethane verses $n$-alkanes. Journal of Applied Polymer Science 42(8): 2321 - 2328.

DOI: http://dx.doi.org/10.1002/app.1991.070420823

14. Kojima Y., Usuki A., Kawasumi M., Okada A., Fukushima Y., Kurauchi T. \& Kamigaito O. (1993). Mechanical properties of nylon 6-clay hybrid. Journal of Materials Research 8(5): $1185-1189$.

DOI: http://dx.doi.org/10.1557/JMR.1993.1185

15. Mathew S. \& Varghese S. (2005). Natural rubber latexbased nanocomposites with layered silicates. Journal of Rubber Research 8(1): 1 - 15.

16. Mathew S., Varghese S., Rajammal G. \& Thomas P.C. (2007). Dipping characteristics of layered silicates-natural rubber latex nanocomposites. Journal of Applied Polymer Science 104(1): $58-65$.

DOI: http://dx.doi.org/10.1002/app.24669 
17. Norrish K. (1972). Forces between clay particles. Proceedings of the $4^{\text {th }}$ International Clay Conference (eds. J.M. Serratosa \& A. Sanchez, 23 - 30 June. University of Madrid, Madrid, Spain, pp. $375-383$.

18. Pendle T.D. \& Gorton A.D.T. (1980). Dipping with natural rubber latex. NR Technical Bulletine. The Malaysian Rubber Producers Research Association. 1-12.

19. Ray S.S. \& Okamoto M. (2003). Polymer/layered silicate nanocomposites: a review from preparation to processing. Progress in Polymer Science 28(11): 1539 - 1641.

20. Stephen R., Alex R., Cherian T., Varghese S., Joseph K. \& Thomas S. (2006). Rheological behaviour of nanocomposite of natural rubber and carboxylated styrene butadiene rubber lattices and their blends. Journal of Applied Polymer Science 101(4): 2355 - 2362.

DOI: http://dx.doi.org/10.1002/app.23852

21. Stephen R., Varghese S., Joseph K., Oommen Z. \& Thomas S. (2006). Diffusion and transport through nanocompsites of natural rubber (NR), carboxylated styrene butadiene
rubber(XSBR) and their blends. Journal of Membrane Science 282(1-2): $162-170$.

22. Utracki I.A. (2004). Clay-containing Polymeric Nanocomposites, $1^{\text {st }}$ edition, pp. 530. Smithers Rapra Publishers, USA.

23. Valadares L.F., Leite C.A.P. \& Galembeck F. (2006). Preparation of natural rubber-montmorillonite nanocomposite in aqueous medium: evidence for polymer-platelet adhesion. Polymer 47(2): $672-678$. DOI: http://dx.doi.org/10.1016/j.polymer.2005.11.062

24. Varghese S. \& Karger-Kocsis J. (2003) Natural rubberbased nanocomposites by latex compounding with layered silicates. Polymer 44(17): 4921 - 4927.

25. Wu Y.P., Wang Y.Q., Zhang H.F., Wang Y.Z., Yu D.S., Zhang L.Q. \& Yang J. (2005). Rubber-pristine clay nanocompsites prepared by co-coagulating rubber latex and clay aqueous suspension. Composites Science and Technology 65(7-8): 1195 - 1202.

DOI: http://dx.doi.org/10.1016/j.compscitech.2004.11.016 